\title{
FACTORS THAT INFLUENCE THE WAYS UNIVERSITY STUDENTS THINK ABOUT REFERENCING AND RELATED CONCEPTS
}

\author{
N.P. Mbutho \\ Department of Wellness Sciences \\ Cape Peninsula University of Technology \\ e-mail: mbuthon@cput.ac.za

\section{Hutchings} \\ Centre for Higher Education Development: Language Development Group \\ University of Cape Town \\ e-mail: catherine.hutchings@uct.ac.za
}

\section{ABSTRACT}

The role and importance of referencing is underestimated and neglected by university students globally. Literature illustrate that poor referencing practices might contribute to the persistent rise of plagiarism in higher educational institutions all over the world. Persistent poor referencing practices observed among our students at one of the South African universities led me to examine the socio-educational and cultural factors that influence the ways university students think about referencing and related concepts. This study interviewed fifteen third- and fourth-year students from one South African University of Technology. Grounded theory coding revealed that despite different cultural and schooling backgrounds, the majority of the students received their first formal referencing training at the university. The students felt that the training provided at our university was not in-depth, practical or extensive enough. Students reported that the reading and writing practices in high school were limited to memorising and regurgitating chunks of text from authoritative texts without necessarily being encouraged to acknowledge sources of information. The students were used to being given all the information considered necessary by teachers in class, and therefore saw no need to search for information themselves. It is therefore imperative that students are introduced to extensive referencing training and be trained to think critically about what they read from the first year of their study through to postgraduate studies.

Keywords: referencing, plagiarism, socio-cultural, socio-educational, university students

\section{INTRODUCTION}

Despite efforts to minimise plagiarism and to improve referencing skills among students, trends of plagiarism are prevalent and continue to affect universities worldwide. International scholars such as Heckler and Forde (2014), Gullifer and Tyson (2010), and McCabe (1999), have indicated that students are not fully aware of what constitutes plagiarism. Similarly, South African scholars, such as Louw (2017), Theart and Smit (2012), and Sentleng and King (2012), 
opine that the majority of South African students are not fully aware of referencing practices and what constitutes plagiarism, and as a result, they continue to plagiarise. Some of the reasons why students plagiarise include the following poor referencing skills, time management, poor writing skills, lack of understanding of what constitutes plagiarism, dissatisfaction with how information on plagiarism and referencing is disseminated to the students and high workloads (Louw 2017; Heckler and Forde 2014; Sentleng and King 2012; Gullifer and Tyson 2010; Lea and Street 1998).

My interest in investigating the socio-educational and cultural factors that might influence the way students think about referencing and related practices is similar to that of some of the international scholars I have explored (Handa and Power 2005; Introna et al. 2003; Currie 1998; Burnette 2002; Pennycook 1996) in terms of examining at the cultural factors that influence plagiarism. However, these studies have usually been conducted in international "western" universities, such as universities in the UK or USA or Australia. These are universities that admit foreign students, such as Chinese, Indian and other foreign students. This study however specifically aimed to explore how factors such as varied and unequal South African educational backgrounds grounded in the unequal political history of South Africa, varied unequal language use in terms of which a particular language is valued the most in our education system, and varied ethnicity and cultural beliefs systems affected how students think about referencing. Angelil-Carter (2000) who is discussed in more detail in the literature review is one of the South African scholars I have explored, who has examined the socio-cultural factors that influence plagiarism.

One expects that, by the time students reach their third year of study, they would be equipped with substantial academic literacy skills such as referencing. However, from my observations as a lecturer, the Bachelor of Technology (B-Tech) students at the Cape Peninsula University of Technology (CPUT) continue to battle with understanding the importance of referencing. Although these students have been at the university for three or more years, they continue to ignore all exhortation and encouragement to reference their work. Although referencing skills are intricate and requires time, effort and attention to detail, one expects that by the time they reach fourth year level, students will have acquired the skill. Given that referencing is crucial for students' success, both while at university and in their future academic pursuits, there is a need to explore the reasons behind their failure both to see its importance and to acquire this skill. In this article I will examine the literature review on the role of referencing in academic and scholarly practices and in combating plagiarism; benefits of referencing; South African cultural and education context. This article also reports on findings of this study which interviewed fifteen students on socio-cultural and educational factors that 
influence the way they think about referencing and related concepts. It will conclude with a summation of the issues raised.

\section{REFERENCING AND PLAGIARISM}

Firstly, let me explain what referencing, and plagiarism is, and how these integrates with academic writing and the discovery of one's own voice. According to Neville $(2007,1)$, referencing is "a practice of acknowledging in your own writing the intellectual property of others' work". It is a given that referencing is essential in academic writing; "Academic writing includes conducting a research enquiry on an unknown subject, identifying meaningful parts of the subject, and then, based on the interpretations, arguing how these parts fit or do not fit together" (Irvin 2010, 10). Irvin (2010) continues to explain that this process of evaluating information includes gathering, analysing, interpreting and synthesising data from different sources with the audience or reader in mind.

This suggests the importance of precisely recording the origin (source) of the information used in the argument (the reference), as this allows the reader to validate an argument. There are many other benefits attributed to referencing; these include giving other scholars an opportunity to evaluate the available literature for themselves and, in the process, develop their critical reading skills. Moreover, referencing distinguishes academic texts such as the journal article from other forms of writing. In addition, most scholars will have more confidence in a referenced academic text than in an unreferenced text as it is assumed that other scholars in the field have critically reviewed the referenced text (Mertens and Baethge 2011). Referencing is one of the important factors which serve to prevent plagiarism.

"Plagiarism involves stealing someone else's idea, language and creativity and its negative consequence is strongly emphasised in higher education institutions" (Williams 2002, 2). In other words, in the academic world the use of language in writing, creating new arguments, and creating new ideas and new knowledge is important, and one needs to learn all possible strategies for the correct ways to avoid plagiarism. Heckler and Forde $(2014,61)$ concur, when they say plagiarism essentially involves copying other individuals' work without attribution. These authors see plagiarism as occurring in a number of areas, such as technology, art, lab work and textual work, and plagiarism as being from journal articles, books and lecture notes. This implies that plagiarism can occur across all disciplines. The definitions above do not include comment on intentional and unintentional plagiarism.

However, Leask (2006) does mention intentional or deliberate plagiarism. Leask defines plagiarism in terms of deliberately taking others' words and ideas and using them as your own. This implies that a person who deliberately plagiarises knows exactly what they are doing and 
is in fact making a choice to steal someone's work without referencing this, hoping not to get caught out. Mertens and Baethge $(2011,550)$ also clearly differentiate between intentional/deliberate and non-intentional/non-deliberate plagiarism. They indicate that "plagiarism is a referencing error where the source of information is intentionally omitted by the author". However, if someone is intentionally removing the referencing then it cannot be referred to as an error, unless they have no clear understanding of the role and importance of in-text referencing within the referencing process. Based on my own experience, I believe that students may omit sources of information or unintentionally plagiarise if they lack referencing skills and lack an understanding of the significance and importance of referencing. This suggests that proper acquisition and valuing of referencing practices is one of the necessary components students need to develop to help minimise their tendency to plagiarise.

\section{THE BENEFITS OF REFERENCING}

Different scholars such as Neville (2010), Wallace and Wray (2011, 9), Mertens and Baethge (2011), Neville (2012), and Hutchings (2014) mention the benefits of referencing that are sometimes not obvious to students. These benefits include the development of an ability to handle vast amounts of information and distinguish your own and other's voices in an argument (Neville 2010). In other words, referencing practice help students develop an ability to selectively, creatively and critically gather, encapsulate and interpret existing information from various sources (books and articles) to inform the future or create new arguments and ideas or theories (Wallace and Wray 2011; Neville 2010; Neville 2012). Hutchings (2014) states that the concept of argument is dominant in the academy and that new ideas and arguments need to be supported by authoritative evidence and multi-voiced argument. She maintains that the practice of referencing contributes greatly to the emergence of voice in students' academic writing. By referring certain ideas to certain sources, students learn and put into practice the skill of using others' voices and learn to identify and use their own voices in their arguments.

Furthermore (Neville 2010) mentions that referencing gives scholars a chance to identify themselves as a member of a social group that share similar values in terms of the academic literacy discourse. Students are introduced in the community of scholars where others are free to interrogate and test the rigor of each other's work. Mertens and Baethge (2011) point out that a referenced academic article distinguishes it from other forms of writing, such as journalism, and gives its content a particular authority, as it has undergone laborious review by other scholars and is supported by literature. They also state that in academic writing referencing is the usual and acceptable way of showing that one has interrogated the literature and is giving other scholars an opportunity to test the rigour of the new argument. 
However, Neville (2007) claims that, although referencing is an expected academic practice in higher educational institutions and has huge benefits, some students find this practice to be laborious and uninteresting for various reasons. Firstly, when students come to the university for the first time, some of them have never been exposed to referencing. Therefore, assuming and expecting that students know about referencing and its importance in the academic discourse is a mistake. Secondly, Neville (2007) says that students have to cope with different and unfamiliar styles of referencing while also dealing with different varieties of interpretation and application by teaching staff, and these need explicit training and more clarity on implementation of the academic integrity policies. Lastly, as Srikumar (2010) says, research, which often begins with a holistic review of the literature, and often requires advanced citing practices, is difficult for new students to comprehend initially when they come to the university. Based on the above information, while it is clear that referencing is an important factor in all academic writing activities, in my experience, convincing students that referencing is important is a momentously difficult task that needs to be addressed daily.

\section{ADDRESSING STUDENTS' RELUCTANCE AND LACK OF INTEREST IN REFERENCING}

Therefore, to address the students' reluctance and lack of interest in referencing, various scholars have made different suggestions. Neville (2010) made the following suggestions. Firstly, the practice of referencing needs to be mandatory for students; these practices need not be enforced in a legalistic manner but made mandatory in an environment that promotes and encourages learning. Secondly, students need to be encouraged and convinced to see referencing from different perspectives rather than just acknowledging others' work. Such as guiding them in collating and synthesising of different voices in creating an argument. Upon realizing the many ways in which they personally benefit from learning how to reference might convince them to learn how to do it. Other scholars, such as Lea and Street (1998), were concerned that students do not understand the relationship between plagiarism and accurate referencing and that this should be made clear to students. They also felt that the emphasis of a lot of the feedback on students' writing was placed on plagiarism in a legalistic Discourse rather than in an educational Discourse. This trend of focusing on legalistic discourse is evident in most of the CPUT documents that address plagiarism.

\section{PERSONAL OPINIONS VERSUS RESEARCH BASED ARGUMENTS}

The documents used in my institution such as the assignment marking rubrics, as well as the plagiarism declarations, are often written in an ultra-formal and threatening manner, including 
the threat of losing marks or facing other unknown consequences. Other documents, such as the programme guides and learner guides that are given to students, are limited to defining what plagiarism is to explaining the consequences of plagiarism. The CPUT policy defines plagiarism and warns students about the consequences of plagiarism as follows: "committing plagiarism is not acceptable to CPUT, and there are serious consequences for any person who is found guilty of plagiarism" (CPUT 2015). While these warnings might be necessary, what these documents lack is the emphasis on the benefits and the importance of referencing such as, improving academic writing skills which is needed throughout university life. The extent to which one reference is actually a show of intellectual force; it shows the lecturer and other readers that you are knowledgeable in your subject matter and are not simply peddling personal opinions. In academic writing, referencing allows us to back our ideas using scientific facts, although these were developed by others. Furthermore, our ideas remain "unscientific" until we can back up our claims with "empirical evidence" and referencing allows us to turn personal opinions into "scientific knowledge". Accurate referencing practices plays a crucial part in avoiding plagiarism in the students' academic writing. These documents also lack any sense of promoting a learning environment for students. Therefore, the benefits to students of referencing which I discussed earlier, as well as the suggestions listed above, need to be considered in the quest to win students' interest in, and enthusiasm towards, referencing and all related academic literacy practices.

\section{UNDERSTANDING AND PERCEPTIONS OF STUDENTS REGARDING PLAGIARISM AND REFERENCING}

As has been mentioned, South Africa is a highly diverse country in terms of culture, ethnicity, language, socio-economic status and its political and education systems. As a result, students come from home and school environments that offer different levels of academic support and different attitudes towards academic literacy practices. This is in fact a global issue. For example, Pecorari and Petric (2014) and Vance (2009) conclude that cultures around the world have varied views regarding the attribution of other people's work in one's own scholarly work. It has therefore been interesting for me to review the existing literature on these views and to explore the findings of other scholars (nationally and internationally) who have evaluated specific socio-cultural and educational influences on literacy practices such as plagiarism, academic integrity, and referencing.

Scholars from international universities which admit foreign students have extensively investigated the role of socio-cultural differences on how students view plagiarism. For example, a study done by Handa and Power (2005) investigated and compared the 
understanding of plagiarism of both postgraduate Indian students' who were currently studying in Australia (and had Indian university undergraduate degree) with postgraduate students' currently studying at the Indian university (with Indian university undergraduate degree). Handa and Power's study aimed to explore possible cultural and educational factors that might contribute to differences in understanding of the notion of academic integrity and plagiarism among these students.

Other studies, such as that of Hu and Lei (2015), Chien (2014), Gu and Brooks (2007), Introna et al. (2003), Currie (1998) and Pennycook (1996), had a similar focus to that of Handa and Power (2005). However, these scholars investigated the various influences of cultural background education on Chinese students' perceptions and understandings of plagiarism. Introna et al. (2003) also examined the cultural background of Greek, Mauritian, Chinese, UK and Indian students and the cultural influences on the instances of plagiarism and related concepts amongst these respective groups of students. While all these studies were done in international universities, my study is investigating if and to what extent socio-cultural factors and the history of inequitable educational backgrounds has an influence on how South African students think about and perceive referencing and related practices. Some South African scholars before me have also investigated the socio-cultural factors influencing academic literacy practices among university students. These scholars include Lumula (2017), Hutchings (2013), McKenna (2010), Verstrate (2006), and Angelil-Carter (2000).

Mckenna (2010), for example identifies some background educational and social factors that might contribute to students' unacceptable literacy practices and their subsequent failure to complete their qualifications. These factors include a schooling system that produces underprepared students. This is especially so in the South African context where, as has been described, other contributing factors, such as the history of Bantu education, an unequal schooling system, and unequal distribution of resources are strong influences.

Hutchings $(2014,312)$ identified possible educational and social factors that might influence adult students" "authorial identity" in their academic writing, their ability to use voice in their academic writing, and their understanding of the reasons behind the importance of referencing. These influential factors include "students having gone through the apartheid and colonial system of education, a system that was transmissive rather than constructive, with little focus on academic literacy skill development" (Hutchings 2014, 314). Most of these students had not done much academic writing by the time they reached postgraduate level of study. These factors would obviously have a negative impact on the progress of these students in terms of new and unfamiliar academic literacy practices and the potential for them to drop out of their courses would be high. 
Furthermore, Angelil-Carter (2000) states that usually the socialisation novice writers receive in terms of their cultural or educational backgrounds has not been included in academic discourse, especially for those students who do not have a good understanding of the English language and, as a result, they might have difficulties using their authoritative voice initially in academic discourse. This might be especially true if one considers the South African history of segregation and unequal educational opportunities. She uses the phrase "alien words" to express the difficulty and unfamiliarity students experience when using academic writing for the first time. She argues that, when students finally decide to try using their own voice, they might continue to use a lot of the authoritative voices of others in their own writing. South Africans especially might struggle with using their own authoritative voice or recognizing others' voices in their own writing, as they may have grown up in homes where they have to speak a different language to that required at school and in a higher education institution. South African students start learning English at different levels, depending which school system they have been exposed to.

For example, some students only start school at age five or six, especially in rural areas. They only start to learn English, which is the main language of learning and Teaching (LoLT) when they start school. Furthermore, depending on the choice of school, some students go to schools where the content is explained using their mother tongue if the teacher understands the mother tongue. This might delay the development of the needed language (English) and might lead to difficulty using their own voice in their academic writing. The same would apply to using memorization as a dominant form of learning for theory tests. Angelil-Carter (2000) goes into detail regarding language issues when she talks about the role of formulaic language in second language acquisition. She says that when a person is learning a new language (English and academic Discourse), the person does not have a sufficient choice of words and therefore summarising, paraphrasing, or detection of different voices when reading an article is difficult.

\section{THEORETICAL FRAMEWORK}

To try to understand the socio-cultural factors that influence how the B-Tech students think about referencing I use the following theories as my framework: Street's ideological model (Street 1993), and Gee's theory of discourse (Gee 1996). Both Gee (1996) and Street (1993) are of the view that individual behaviour and cognition in relation to literacy is best studied by taking into consideration the social and cultural practices of which they are a part (Gee 1998). Gee $(1996,131)$ defines "discourse as a socially acceptable association among ways of using language, thinking, feeling, believing, valuing and acting that can be used to identify oneself as a member of a socially meaningful group or social network". This implies that, when examining 
how students view literacy practice in higher education institutions, we need not look only at proper textual usage of language (in terms of referencing), but also at what other socio-cultural factors influence their behaviour/thinking (whether acceptable or not) and also what needs to be done for them to be accepted into the new university discourse. In his Ideological model Street (1993) concurs with Gee (1996) when he says, although acquiring a literacy skill and the cognitive aspects of literacy is important, understanding the influence of the "cultural whole and within power and position" on literacy practices is also important (Street 1993, 9).

\section{METHODOLOGY}

The main research question for this study was: what background, socio-educational and cultural factors influence how B-tech students think about referencing and related concepts? To answer this question the study employed an exploratory qualitative research design. After ethical approval, open-ended and in-depth semi-structured face to face interviews were conducted to gather qualitative data from third- and fourth-year students from one of the South African universities of technology. The interview protocol comprised of the following sub-questions:

1) How were reading and writing skills encouraged at your high school as compared to university?

2) When did you first learn about referencing?

3) What feedback did you get on referencing in your assignments at school?

4) What feedback did you get on referencing in your assignments at university?

5) Do you think differences in culture and power structures in society influence the way students think about referencing?

These sub-questions were further divided into more probing questions, and aimed at answering the main question. The fifteen participants from different schooling systems, different ethnic backgrounds, different provinces, and who spoke a variety of languages were purposefully selected and therefore could potentially provide rich data based on their unique educational backgrounds and cultural experiences. The difference in student's socio-cultural and socioeducational background is illustrated in Table 1.

Table 1: The demographic profile of the participants

\begin{tabular}{|c|c|l|l|c|c|}
\hline Participant & Type of School & Province & Ethnicity & Home Language & Age \\
\hline P1 & Model C & EC & Coloured & Afrikaans & 23 \\
\hline P2 & Private & EC & Black & isiXhosa & 23 \\
\hline
\end{tabular}




\begin{tabular}{|c|l|l|l|l|c|}
\hline Participant & Type of School & Province & Ethnicity & Home Language & Age \\
\hline P3 & Model C & WC & Coloured & Afrikaans & 25 \\
\hline P4 & Public & WC & Black & isiXhosa & 27 \\
\hline P5 & Public & EC & Black & isiXhosa & 22 \\
\hline P6 & Public & GAUTENG & Black & Setswana & 24 \\
\hline P7 & Model C & WC & Coloured & Afrikaans & 24 \\
\hline P8 & Private & EC & Black & isiXhosa & 24 \\
\hline P9 & Public & WC & Coloured & Afrikaans & 27 \\
\hline P10 & Public & WC & Black & isiXhosa & 26 \\
\hline P11 & Model C & WC & Coloured & Afrikaans & 20 \\
\hline P12 & Public & WC & Black & isiXhosa & 21 \\
\hline P13 & Private & EC & Black & isiXhosa & 27 \\
\hline P14 & Private & EC & Coloured & Afrikaans & 55 \\
\hline P15 & Public & WC & Wfrikaans & 22 \\
\hline
\end{tabular}

EC - Eastern Cape, WC - Western Cape, Model C - fee-paying schools funded by the South African government were previously white schools only and prevalent in urban areas, Public - schools fully funded by the South African government and prevalent in rural areas, Private - privately owned schools not funded by the South African government and prevalent in urban areas.

The elements of the Grounded Theory coding (GTC) were used to analyse the qualitative data. These elements included manual line by line coding followed by focused coding also referred to as selective coding as recommended by Charmaz (2014). Initially I read each transcript several times to familiarised myself with the data. I then named each line from the transcript with the words that reflect action. Charmaz $(2014,48)$ recommends coding using words that reflects action to avoid "tendencies to make conceptual leaps and to adopt to external theories before we have done the analytical work". After the initial codes were identified, I moved on to selective or focused coding. This helped reduce the initial codes further by selecting the most significant and the most frequent codes. This process helped sort, synthesise, integrate and organise data and made it manageable to interpret as suggested by Charmaz (2006).

\section{RESULTS AND DISCUSSION}

This study aimed to explore whether and to what extent the background socio-educational and cultural factors of a sample of B-Tech students influenced how these students perceived and thought about referencing and about related academic literacy concepts. As was described earlier, South Africa is a multi-cultural country with many different languages, cultural values, and has a history of unequal and inequitable educational systems, hence my core interest was on the background experiences of these students. The investigation was conducted, at every stage of the research, taking into consideration the objectives of the study. The objectives included to explore the many and various factors that influence how a sample of B-Tech students think about referencing and related concepts, including socio-educational background and socio-cultural factors. In the objectives we included an investigation of where and when in 
their education paths the participating B-Tech students were initially formally introduced to referencing and related concepts, and how and to what extent their experience of this affected the way they think and act about referencing, what the B-Tech students views were of the importance and value of referencing, and to explore the participating students' understanding of what constitutes referencing.

I felt that this topic needed to be explored in order to understand why so many students at CPUT continue to battle with grasping referencing practices and related concepts even after three or more years at the university. While a once-off training session is provided on referencing within the first month of first year students arriving at the university, the students are reluctant - or unable to - implement the referencing skills - supposedly learned - in their own work. One would assume - or it is assumed by the institution - that after such training the students would be able to integrate the skill in their academic Discourse. However, this has been found not to be so, as many third- and fourth-year students in my class continue to plagiarise in their academic assignments.

Subsequently, to help provide an answer to the research question and the research objectives, data were collected and analysed from verbatim interview transcripts in conjunction with a review of existing literature on the topic of my research. A summary of the discussion on the findings of the study, together with recommendations, is provided below:

\section{SOCIO-EDUCATIONAL AND CULTURAL FACTORS}

The socio-cultural and educational factors that seem to influence the referencing practices of the 15 students participating in this study included, lack of academic reading and writing in high school, and, in part, during the first years of university, poor language proficiency, and dependency and trust on authoritative figures and resources (teachers, lecturers, textbooks) to be the providers of all needed information.

As far as reading and writing across all background educational systems is concerned, the data revealed that most of the participating students had not been exposed to critical academic reading and writing in high school. The students were only exposed to "creative" (nonacademic) reading and writing for the purpose of language development (Xhosa, Afrikaans and English). The students' reading and writing practices in language classes were sometimes monitored at school through written essays, reading aloud, giving feedback to teachers on literature read, and oral presentations. However, at the university they experienced reading and writing as becoming more self-directed and, unlike at high school, there were no monitoring systems.

As far as other high school subjects that are not language related were concerned, such as 
Natural Science or History, students read only allocated textbooks and the class notes that were provided to them in preparation for the assessments at school. This pedagogical practice disadvantaged students as they were not exposed to different kinds of literature such as encyclopaedias, research articles, research books, the internet, and policies. The students in the current study reported that in high school they were only exposed to textbooks and lecture notes, and only a few students used on-line sources such as Google and Wikipedia. Consequently, when the students came to university, they battled in their researching and reading and assimilating of academic books and research articles as they had never been exposed to this kind of literature.

The students reported that they were not used to the increase in the load of reading and writing and for the first time they were required to read more than one textbook in preparation for their academic projects. These students reported that they had never been encouraged to find their own information at school and as a result they struggled with their search for different sources of literature as they were used to using their one allocated textbook for each subject, and internet sites such as Google and Wikipedia for learning and for assignments. The concept of using their own voice and recognising the voices of other researchers when writing was very difficult to comprehend, considering that, apart from this being a new and unfamiliar concept, for all of the students in the study sample English was not their mother tongue and they were not used to collating information from more than one or two books. The use of only one or two books to prepare for an assignment in high school, and in some cases in the first and second year of their diploma course, militated against the student's learning the skill of synthesising large text from various books and academic articles.

As a result, these students missed many learning opportunities, a situation mentioned by various scholars in this field. For example, scholars such as Hutchings (2014), Wallace and Wray (2011) are of the view that, in order to create a credible argument, students need to critically engage extensively, and in an ongoing way, with existing literature in the field/knowledge area they are writing about. This cannot be achieved at university level by reading one or two textbooks; it can only be achieved by referring to a sizeable number of academic sources. The studies mentioned found that, through this engagement with a range of academic sources, students learn many things: they learn how to find credible sources, how to reference properly, how to synthesise information, to use their authoritative voice, and to identify the voices of other researchers in academic writing, and, in the course of this, they discover different ways of avoiding plagiarism.

Based on these findings one needs to take into consideration what Mckenna (2010) says about educational inequality and unacceptable literacy practices. Mckenna (2010) suggests that, 
considering the South African history of inequality and marginalisation of the poor and underprivileged, we should celebrate when these "disadvantaged" students manage to reach university level. She also mentions that these students might bring unacceptable academic literacy practices and that our duty should be to make explicit to these students the value and importance of the acceptable literacy practices, and apprentice them into the new academic practices to minimise dropout, and to help these students catch-up with their fellow - more privileged - students.

As far as dependency on their superiors is concerned, students felt that at the time they preferred that, or did not question that, the teacher at school provided them with all the required information about the subject instead of their researching their own information on a new topic. The students reported that they trusted their teachers to provide them with all the information they needed to succeed. This culture of dependence and unquestioning respect for authority was evident from all the participating students from different school backgrounds. Students in the study reported that they trusted their superiors to provide them with all the required information uncritically and without question. Understanding and the ability to memorise the provided content seemed to be what was valued more, rather than questioning the integrity or validity of the information.

The culture of dependency on those in positions of power and control (teachers, textbook writers) was both strong and endemic at their high schools. This culture deprives a student of the opportunity to learn how to create a meaningful argument and to trust his/her own authoritative voice. One has to wonder whether some of the African cultural value systems do not contribute to this dependency, especially among those students from rural schools. For example, the highly valued philosophy of Ubuntu, which teaches young African individuals, both at home and in public spaces, to value and respect the authority of their elders and superiors (teachers and lecturers in this case) without question, whether these elders are educated or not (Lefa 2015; Khomba and Kangaude-Ulaya 2013). Consequently, students growing up in this cultural context may see themselves as receivers of knowledge from those who are considered wise and intelligent rather than as the creators of knowledge. While this is speculation, and the current study does not provide a clear indication of the influence of this philosophy, its influence on the attitudes and values of students in an academic context needs deeper investigation.

Furthermore, in line with the Constitution of Republic of South Africa (1996) and the Language in Education Policy (1997), South Africa promotes multilingualism in order to show respect for all eleven official languages and the speakers of these. As a result, some students have had to learn three languages at school (mother tongue, English and Afrikaans), especially 
if they attend Model C schools. In rural public schools students are required to learn and develop their mother tongue and English. This might have implications for their English language proficiency, depending on their family and educational background. Some scholars, such as Angelil-Carter (2000) and Burnette (2002) have identified poor English language proficiency as one of the contributing factors to unintentional plagiarising as students battle with paraphrasing and summarising, and lack the confidence to use their own voices in a written text. Although this study does not explicitly identify South African cultural and educational practices and poor language proficiency as the actual reasons for poor referencing skill, these factors might have an influence on, and contribute towards, how students perceive and think about referencing and related concepts.

While all students in the study sample reported that they preferred their teachers to give them all the information in class while they were at school and that the same applied to their lecturers when they were in their first and second year of study at the university, a few students in the sample saw the benefit in finding information for themselves on a particular topic, especially at B-Tech level when the research modules were introduced. However, the majority of these students still preferred to be given and to passively receive all information even at the university.

\section{VIEWS ABOUT THE IMPORTANCE OF REFERENCING}

With respect to participating students' views on the importance of referencing, the majority of the students viewed referencing as important. However, many of these students reported that they did not fully comprehend how and why referencing was beneficial to their own academic writing specifically. Although they acknowledged the importance of referencing, when asked why they thought referencing was important, they provided various reasons pertaining to acknowledging and crediting others, locating texts, and avoiding plagiarism. They did not mention any of the following benefits: the improvement of academic writing skills, the development of an ability to handle vast amounts of information and to distinguish their own and other's voices in an argument, and the improvement of their own critical writing and argumentative skills and practices. Similar to these findings, Park (2003), in a study conducted in the UK, found that the importance of plagiarism and referencing was not always apparent or rendered explicit to the students in his study. The results of his study, as with those of the current study, would suggest that these benefits need to be made explicit when students come to university through training and continuous practice and interaction in the classroom.

\section{UNDERSTANDING REFERENCING AND ITS CONSTITUENTS}


While students in the current study understood what referencing means, they did not grasp the full detail of the practice. Most of students in the sample were not able to differentiate between a reference list, a bibliography, and citation, and could not see how these concepts relate to each other. While these students also understood that referencing was about acknowledging the work of others in their own writing, they did not understand the value of referencing for themselves in their own writing including the value of helping them identify a gap in the field, and one to which they could then contribute by doing their own research in that area. Gullifer and Tyson (2010), Gu and Brooks (2007), Devlin and Gray (2007) and Ashworth, Bannister and Thorne (1997) all observed similar results with their participants: the participants understood what plagiarism is; however, they had a problem identifying in full what constitutes plagiarism. For example, students in the study done by Gullifer and Tyson (2010) had little insight into the scholarship of the importance of citation and attribution to authenticate their own work, and they battled with the idea of intertextuality and ownership of ideas. Moreover, students in Lea and Street (1998) study lacked clarity with regards to the relationship between plagiarism and correct referencing. This remains a serious concern 20 years later, as students need to understand the relationship between referencing, plagiarism and academic writing in order to succeed in academic institutions.

Students in the current study acknowledged that they all used the Harvard style of referencing; however, when they were asked to explain how to use the Harvard style of referencing, they provided inconsistent technical descriptions of how to reference using this style. Mertens and Baethge (2011), and Pears and Shields (2008), emphasise that it is crucial for academic writers to ensure that the references in their work are formulated precisely and accurately. They point out that this makes it easy and quick for other scholars in the field to access the information and encourages knowledge sharing within the academic community. These studies suggest the need for technical referencing skills to be learnt and practised by students on a continuous basis in order for them to learn and fully acquire and be able to use these skills and practice and that teaching strategies to deal with students' apparent lack of understanding of, and ability to apply, of these practices are needed.

\section{FIRST FORMAL REFERENCING TRAINING}

Unfortunately, the students in the current study reported that they had never had training in these practices in high school. Some of them said that they were only instructed to reference, but were not really taught how to reference nor why referencing was important. Similarly, students in the McCabe (1999) study on academic dishonesty amongst US students, reported that students in the study had been exposed to almost no discussion or teaching about 
referencing in their schools. Students participating in the current study reported that referencing was only mentioned briefly during orientation at the beginning of the year, that they experienced formal referencing training for the first time in university (CPUT). Consequently, these students found the skill too overwhelming and difficult to learn in the short space of time. Usually at this institution the training happens during the orientation period, in the first term of the first year. Furthermore, these students felt that the training was not sufficient and that they should be given an opportunity to practice, learn and gradually acquire and use the skill correctly and in a beneficial way. The findings in this study are not unique: participants in Devlin and Gray (2007) study, conducted in Australia, also felt that referencing and plagiarism training was inadequate and resulted in poor understanding of the referencing Moreover, university students in Gullifer and Tyson (2010) study reported that discussions about plagiarism were only conducted at the beginning of the year and no further discussion or learning workshops were provided after that. These studies, together with the current study, suggest that this issue needs to be addressed urgently taking into consideration the complex nature of the referencing skill and its relationship to other academic concepts and conventions that also need to be acquired such as the awareness of plagiarism and academic writing practices. The studies also suggest that expecting students to learn these concepts overnight, or by osmosis, is unrealistic and that lecturers need to be mindful of this when dealing with students entering higher education institutions and academic Discourse communities.

Moreover, the majority of the students participating in the current study reported that they had never received feedback about referencing, or on their attempts at referencing, at school. This was because they were never specifically taught how to reference in high school. At the university, they reported that feedback from lecturers was sometimes not sufficiently detailed or specific. The feedback mainly focussed on incorrect format and warnings about the seriousness of plagiarism without explaining the importance of referencing and the specific implications of plagiarism for academic research. Students were also instructed to use electronic applications to check for plagiarism in their document. These findings would suggest that training is needed for lecturers as well as students in referencing and on how to provide effective and useful feedback to students. The findings also suggest the need for assessment strategies to be evaluated to check whether and what specific ways they provide an opportunity for the students to build their academic literacy skills. Moreover, the conditions around the provision of feedback need to be evaluated as results from other scholars such as Heckler and Forde (2014) showed that excessive work loads of lecturers were not conducive to their providing much needed developmental feedback on the content of students' work as well as referencing skills and practices. The findings of the current study suggest that such shortcomings need to 
be evaluated amongst the CPUT staff as well.

\section{CONCLUSION}

This study has concluded from the findings that some socio-cultural and educational background experiences such as lack of encouragement of academic reading and writing as well as lack of formal referencing and plagiarism training has led to difficulties of students in the study sample adapting to the demands of the university concerning academic literacy practices. Other factors, such as dependency on superiors, and on the provided textbooks also resulted in students battling to understand the role and value of referencing in academic writing and its role in the prevention of plagiarism, including the lack of understanding of plagiarism itself. Furthermore the study concludes that, although there is a form of training offered to first year students in the first term at the university, the students participating in the study felt that the training did not achieve its purpose, and that, as a result, students did not understand, or had acquired only a limited understanding of the concept of referencing and were not really clear in terms of its benefit in their academic lives. Therefore, they recommended, as I have stated earlier, that the training period be extended and that more practical sessions on referencing in a learning environment be implemented.

\section{REFERENCES}

Angelil-Carter, S. 2000. Stolen language? Plagiarism in writing. London: Pearson Education.

Ashworth, P., P. Bannister and P. Thorne. 1997. Guilty in whose eyes? University students' perceptions of cheating and plagiarism in academic work and assessment. Studies in Higher Education 22(2): 187.

Burnette, S. 2002. Dishonor and distrust. Community College Week 14(24): 6-8.

Cape Peninsula University of Technology. 2015. CPUT plagiarism policy. http://libguides. library.cput.ac.za/research (Accessed 12 August 2018).

Charmaz, K. 2006. Constructing grounded theory: A practical guide through qualitative analysis. London: Sage publication.

Charmaz, K. 2014. Constructing grounded theory. $2^{\text {nd }}$ Edition. London: Sage publication.

Chien, S. C. 2014. Cultural constructions of plagiarism in student writing: Teachers' perceptions and responses. Research in the Teaching of English 49(2): 120-140.

Constitution of Republic of South Africa. 1996. Act No 108 of 1996. Government Gazette 378(17678). 18 December. Government notice no. 2083. Cape Town. Government printer.

Currie, P. 1998. Staying out of trouble: Apparent plagiarism and academic survival. Journal of Second Language Writing 7(1): 1-18.

Devlin, M. and K. Gray. 2007. In their own words: A qualitative study of the reasons Australian university students plagiarise. Higher Educational Research and Development 26(2): 181-198.

Gee, J. P. 1996. Social linguistics and literacies: Ideology in discourses. London: Falurer Press.

Gee, J. P. 1998. The new literacy studies: From "socially situated" to the work of the social. University of Wisconsin at Madison. Madison: Wisconsin. 
Gu, Q. and J. Brooks. 2007. Beyond the accusation of plagiarism. System 36: 337-352.

Gullifer, J. and G. A. Tyson. 2010. Exploring university students' perception of plagiarism: A focus group study. Studies in Higher Education 35(4): 463-481.

Handa, N. and C. Power. 2005. Land and discover! A case study investing the cultural context of plagiarism. Journal of University Teaching and Learning Practise 2(3): 65-84.

Heckler, N. C. and D. R. Forde. 2014. The role of cultural values in plagiarism in higher education. Journal of Academic Ethics 13: 61-75.

Hu, G. and J. Lei. 2015. Chinese university students' perceptions of plagiarism. Ethics and Behaviour 25(3): 233-255.

Hutchings, C. 2014. Referencing and identity, voice and agency: Adult learners' transformations with literacy practices. Higher Education Research and Development 33(2): 312-332.

Introna, L., N. Hayes, L. Blair and E. Wood. 2003. Cultural attitude towards plagiarism: Developing a better understanding of the needs of students from diverse cultural backgrounds relating to issues of plagiarism. Lancaster University.

Irvin, L. L. 2010. What is academic writing? In Writing Spaces, ed. C. Lowe and P. Zemliansky, 3-17. Indiana: Parlos Press.

Khomba, J. K. and E. C. Kangaude-Ulaya. 2013. Indigenization of corporate strategies in Africa: Lessons from the African Ubuntu Philosophy. China-USA Business Review 12(7): 672-689.

Lamula, S. P. 2017. Students' understanding, perceptions and experiences of plagiarism: A case study of the University of KwaZulu Natal Pietermaritzburg campus. Unpublished Masters dissertation. University of KwaZulu-Natal, Pietermaritzburg.

Language in Education Policy. 1997. Announcement by the Minister of Education, 14 July 1997. https://www.education.gov.za/Resources/Policies.aspx (Accessed 10 October 2018).

Lea, M. R. and B. Street. 1998. Student writing in higher education: An academic literacy approach. Studies in Higher Education 23(2): 157-172.

Leask, B. 2006. Plagiarism, cultural diversity and metaphor-implications for academic staff development. Assessment and Evaluation in Higher Education 31(2): 183-199.

Lefa, B. J. 2015. The African philosophy of ubuntu in South African education. Studies in Philosophy and Education 1(1): 15.

Louw, H. 2017. Defining plagiarism: Students and staff perceptions of a grey concept. South African Journal of Higher Education 31(5): 116-135.

McCabe, D. L. 1999. Academic dishonesty among high school students. Adolescence 34(136): 681687.

McKenna, S. 2010. Cracking the code of academic literacy: An ideological task. Beyond the university gates: Provision of Extended Curriculum Programmes in SA, 8-5.

Mertens, S. and C. Baethge. 2011. The virtues of correct citation. Deutsches Arzteblatt International. 108(33): 550-552.

Neville, C. 2007. The complete guide to referencing and avoiding plagiarism. Berkshire England: Open University Press.

Neville, C. 2010. The complete guide to referencing and avoiding plagiarism. $2^{\text {nd }}$ Edition. Berkshire England: Open University Press.

Neville, C. 2012. Referencing: Principles, Practice and Problems. RGUHS J Pharm Sci 2(2): 1-8.

Park, C. 2003. In others (people's) words: Plagiarism by university students-literature and lessons. Assessment and Evaluation in Higher Education 28(5): 471-488.

Pears, R. and S. Shields. 2008. Cite them right the essential referencing guide. Newcastle: Pears Tree Books.

Pecorari, D. and B. Petric. 2014. Plagiarism in second language writing. Language Teaching 47(3): 
269-302.

Pennycook, A. 1996. Borrowing others' words: Text, ownership, memory, and plagiarism. Teachers of English to Speakers of Other Languages Quarterly 30(2): 201-230.

Sentleng, M. P. and L. King. 2012. Plagiarism among undergraduate students in the Faculty of Applied Sciences at a South African Higher Education institution. South African Journal of Libraries and Information Science 78(1): 57-67.

Srikumar, B. N. 2010. Reference style and common errors with referencing. In Biomedical Research: From ideation to publication, ed. B. N. Srikumar, 479-488. Wolters Kluwer, Lippincott Williams and Wilkins.

Street, B. 1993. Cross-cultural approaches to literacy. Cambridge: Cambridge University Press.

Theart, C. J. and I. Smit. 2012. The status of academic integrity amongst nursing students at a nursing education institution in Western Cape. Curationis 35(1): 1-8.

Vance, N. 2009. Cross-cultural perspectives on source referencing and plagiarism. English as a second language cross cultural perspectives on source referencing and plagiarism. EBSCO Research Starters, 1-6.

Verstrate, C. 2006. Plagiarism: The cultural outbreak. Masters: Mini dissertation. University of Cape Town.

Wallace, M. and L. Wray. 2011. Critical reading and writing for postgraduates. London: Sage.

Williams, J. B. 2002. The plagiarism problem: Are the students entirely to blame. In Proceedings $19^{\text {th }}$ ASCILITE conference, 1-10. 